\title{
Turner syndrome and morgagni hernia in newborn: A case report
}

\author{
Sugely Velasco-Terrones ${ }^{1 *}$, Ricardo García Cavazos ${ }^{2}$, Mario Pineda-Ochoa ${ }^{3}$, Lino Cardiel-Marmolejo ${ }^{4}$ and \\ José Manuel Ortega-Cruz ${ }^{5}$ \\ ${ }^{1}$ Servicio de Neonatología; ${ }^{2}$ Asesor; ${ }^{3}$ Servicio de Neonatología; ${ }^{4}$ Dirección de Educación y Capacitación en Salud; ${ }^{5}$ Servicio de neonatología. \\ Hospital General de México "Dr. Eduardo Liceaga”, Mexico City, Mexico
}

\begin{abstract}
Turner syndrome is identified by the combination of a number of phenotypic findings at birth as lymphedema of hands and feet, "pterygium colli," shield chest, congenital cardiopathy, and characteristic morphological data birth whose etiology is supported in the cytogenetic study that determines the total absence of an X chromosome, monosomy of chromosome X, (45, X), identified in $40-60 \%$ of cases. It is one of the most frequent chromosomal abnormalities. Congenital diaphragmatic hernia $(C D H)$ is a common birth defect. $2 \%$ occur in the anterior Morgagni orifice, the etiology of the majority of the cases remains unknown, but there is growing evidence of genetic causation, the data are supported by the association with recurrent chromosomal abnormalities and the existence of multiple transmission families of $\mathrm{CDH}$; however, there are not many records in association with total or partial monosomy of chromosome $X$, reason for this report.
\end{abstract}

Key words: Turner syndrome. Morgagni hernia. Diaphragmatic hernia.

\section{Introduction}

Turner syndrome (TS) is defined as the combination of a series of characteristic physical findings and the total or partial absence of an X chromosome. It is one of the most frequent chromosomal abnormalities. It affects approximately $3 \%$ of all female fetuses and has an approximate incidence of 1 per 2500 newborn women. $50-60 \%$ of the cases demonstrate a monosomy or complete absence of $\mathrm{X}$ chromosome (45 X), and in most of the times, the lost $X$ chromosome is of paternal origin. In $20 \%$ of cases, structural alterations are found in $\mathrm{X}$ chromosome (partial monosomy) as major deletions, microdeletions, isochromosomes, or ring chromosome. The remaining $20 \%$ are patients with the presence of two or more cell lines derived from the same zygote (mosaicism), and in at least one of them, there are numerical or structural alterations of an $\mathrm{X}$ chromosome.

The clinical spectrum of TS is very variable. Although no isolated finding is specific, they confer a very characteristic phenotype as a whole, among the characteristics are anomalies in the development of the bones of the face: retrognathia, micrognathia, and underdeveloped maxilla which is responsible for the dental malocclusion in an ogival palate. Other common facial features are palpebral ptosis, strabismus, fine upper lip with drooping commissures, epicanthus, and low implantation of the auricular pavilions. One of the most typical findings in the neonatal period is the presence of lymphedema, a consequence of an alteration in the lymphatic drainage. This anomalous lymphatic drainage affects the formation of other organs, leaving other sequelae such as pterygium
*Correspondence:

Sugely Velasco-Terrones

E-mail: sugely_@hotmail.com
Available online: $21-03-2019$ Rev Med Hosp Gen Mex. 2019;82(1):50-54 www.hospitalgeneral.mx 0185-1063/@ 2018 Sociedad Médica del Hospital General de Mexico. Published by Permanyer México SA de CV. This is an open access article under the CC BY-NC-ND license (http://creativecommons.org/licenses/by-nc-nd/4.0/). 


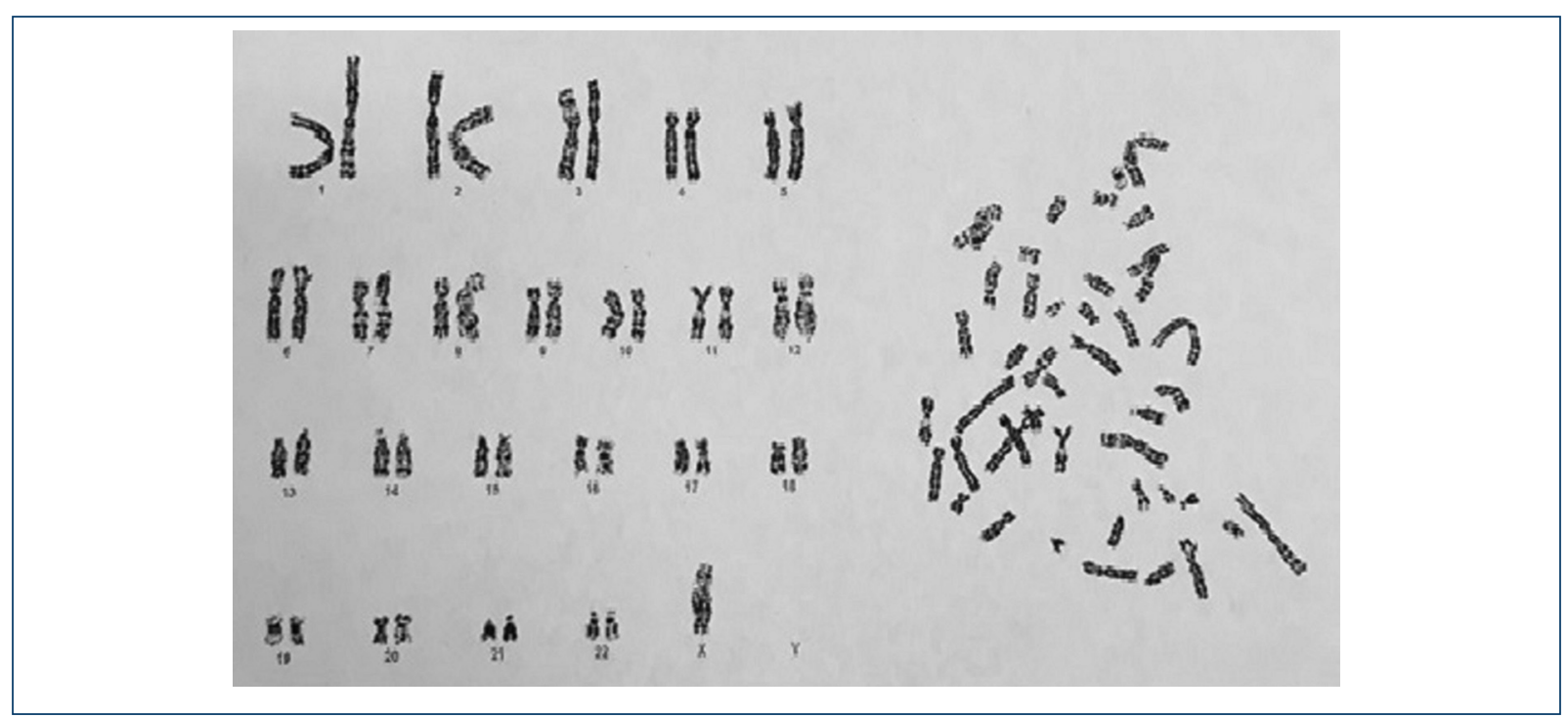

Figure 1. Karyotype from amniotic fluid. 30 metaphases were analyzed with GTG banding technique and chromosomal resolution from 375 to 400 bands. A 45X chromosomal complement was found.

colli or winged neck that comes from the nuchal hygroma present during fetal life: the reabsorption of the same results in the characteristic skin folds of the neck as well as the low implantation of the hair and the detachment of the auricular pavilions. A characteristic feature is the widening of the thorax and shoulders sometimes associated with pectus excavatum. The short thorax and the widening result in an increase in the intermamillary distance (teletelia). The short stature is an almost constant sign, other characteristics of this syndrome are intrauterine growth retardation, slow growth from early childhood, and absence of the outbreak of pubertal growth with delayed bone maturation.

TS is associated with other pathologies or diseases, cardiovascular disorders are the most frequent and are usually present in up to $50 \%$ of patients. The most frequent congenital heart diseases are aortic coarctation and bivalve aorta. The main causes of prenatal mortality secondary to congenital heart defects are hypoplastic left heart syndrome and/or hypoplastic aorta ${ }^{1}$. There may also be renal alterations and autoimmune diseases ${ }^{2,3}$.

The anteromedial diaphragmatic defect through the Morgagni hole "Hernia de Morgagni" represents $2 \%$ of the diaphragmatic hernias. Defect produced by the lack of fusion of the sternal and crural portion of the diaphragm, being more frequent that of the right side $(90 \%)$, they can be bilateral. The hernia sac usually contains the transverse colon, the small intestine, or the liver. The majority of children with this defect are asymptomatic and are diagnosed after the neonatal period, the defect is detected incidentally or is identified as part of the diagnostic approach of respiratory symptoms (tachypnea) and intestinal symptoms such as abdominal pain, vomiting, or constipation. Chest radiography is usually the study in which the defect is identified during the neonatal period, where a structure is identified behind the cardiac silhouette and the lateral projection allows this structure to be located in the retrosternal area. There may be other alterations or syndromes associated with Morgagni's diaphragmatic defect, among which are intestinal malrotation, esophageal atresia, omphalocele, trisomy 21, 18, and 13, Beckwith-Wiedemann syndrome, and Goldenhar syndrome ${ }^{5,6}$.

\section{Clinical case}

Female newborn product of the second gestation; mother of 19 years old, regular prenatal control, at 14 weeks of gestation the prenatal ultrasound reports hydrops fetalis, continuing prenatal follow-up in the gynecology-obstetrics service of the General Hospital of Mexico "Dr. Eduardo Liceaga" O.D., where amniocentesis and amniotic fluid karyotype is performed, reporting a 45X chromosomal complement (Fig. 1), later enrolled with normoevolutive pregnancy. It is born vaginally, meconium amniotic fluid ++ , and non-vigorous product, it is aspirated by air, and a ventilation cycle with positive pressure is applied, Apgar 6/7, weight at birth $3000 \mathrm{~g}$, height $49 \mathrm{~cm}$, and gestational age by Capurro (37.6). 


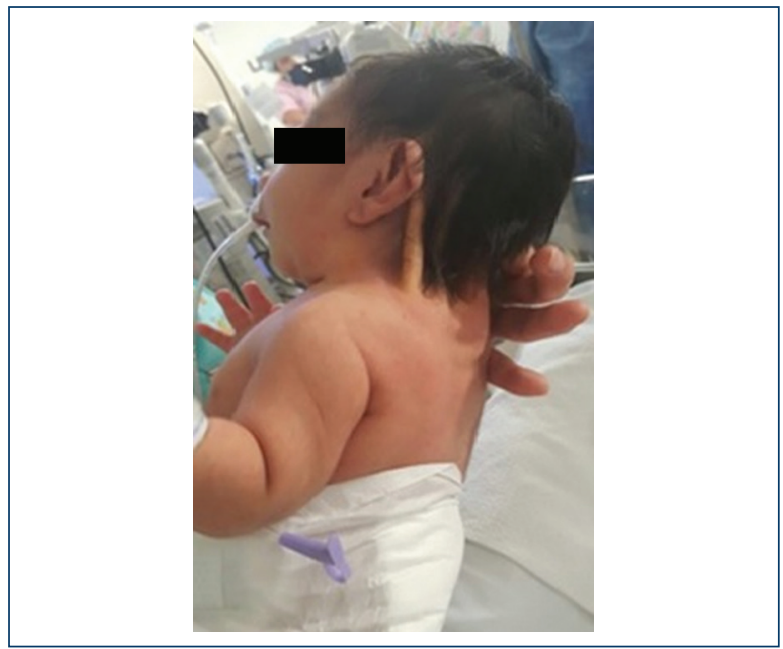

Figure 2. Presence of pterygium colli and micrognathia.

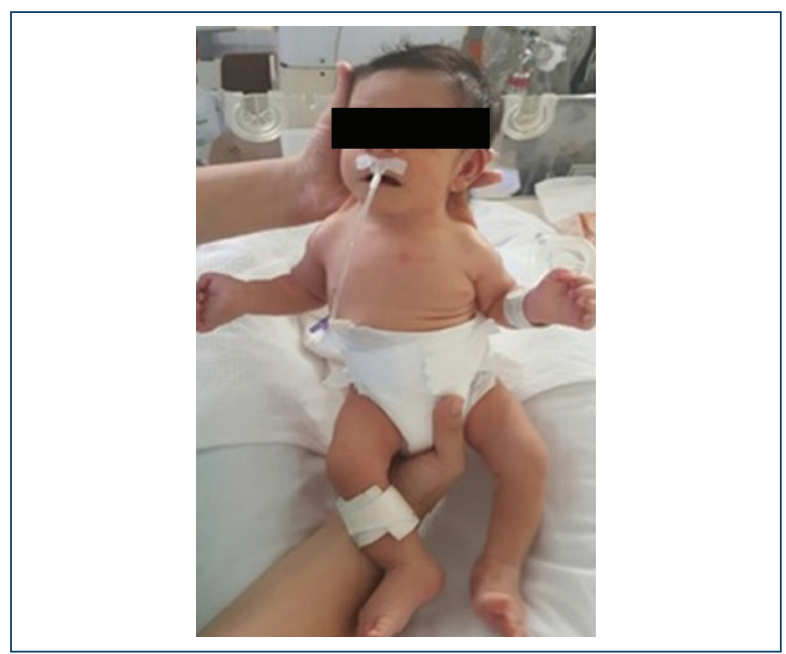

Figure 3. Neonate with the presence of palpebral ptosis, widening of the thorax with teletelia.

The physical examination revealed dolichocephalic skull, anterior fontanelle of $2 \mathrm{~cm} \times 1 \mathrm{~cm}$, telecanthus, palpebral ptosis, low implantation of auricular pavilions, micrognathia, pterygium colli (Fig. 2), enlarged thorax, teletelia (Fig. 3), heart sounds and pulmonary fields without alterations, full limbs, lymphedema of hands and feet, adequate muscle tone, anus, and esophagus watertight; the rest of the physical examination without alterations.

At $10 \mathrm{~min}$ of age, she started with respiratory distress, Silverman-Andersen of 2 (mild nasal flaring and discrete intercostal drainage) so that she was admitted to the neonatal intermediate therapy service, where the following study approach was performed: support with

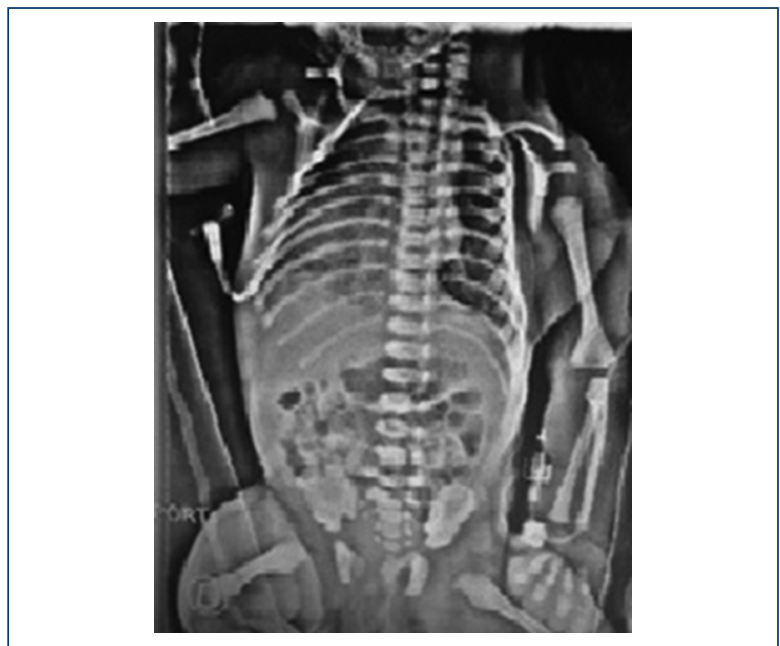

Figure 4. Radiopaque image with opacity in the right basal hemithorax.

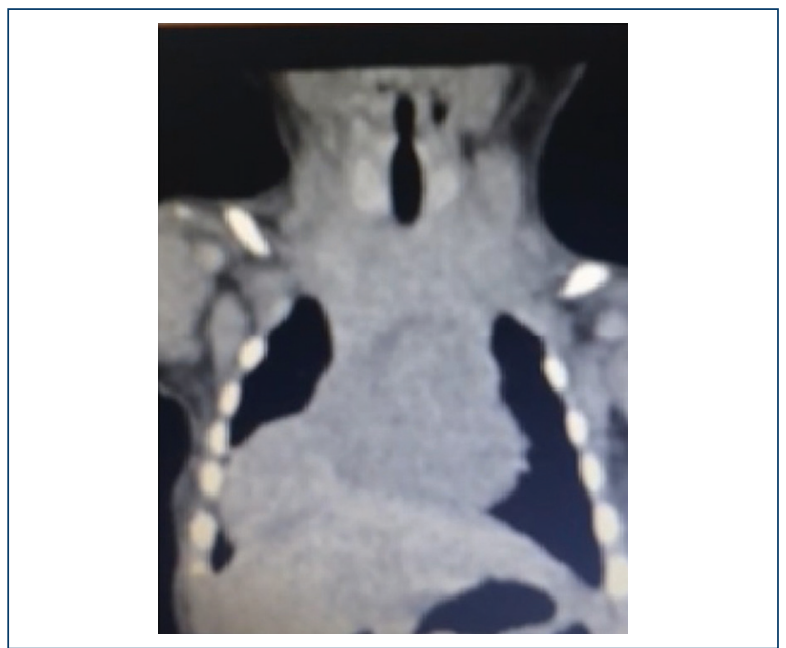

Figure 5. AngioTAC image correlating pleuropericardial cyst.

supplementary oxygen with a cephalic helmet with $\mathrm{FiO}_{2}$ $28-40 \%$, thoracoabdominal radiography is performed (Fig. 4) for persisting with tachypnea, where opacity is observed in the right hemithorax basal area, so angiography of the thorax is performed (Fig. 5) that reports images related to pleuropericardial cyst. An echocardiogram is performed that reports: $5 \mathrm{~mm} \times 2 \mathrm{~mm} \times 1 \mathrm{~mm}$ patent ductus arteriosus without hemodynamic repercussion, pulmonary normotension with PSAP $19 \mathrm{mmHg}$, and ventricular function conserved with $65 \% \mathrm{FEVi}$. The service of pediatric surgery is evaluated by those who perform thoracotomy with diaphragmatic plasty with Morgagni Hernia with a $4 \mathrm{~cm} \times 3 \mathrm{~cm}$ defect, no 
complications are made during the procedure; it is possible to remove the support with supplemental oxygen 8 days after surgery. It is discharged 20 days after the surgical procedure, without the need for supplemental oxygen and in adequate conditions.

\section{Discussion}

TS was described in 1938 by Henry Turner. In 1958, Ford found that these patients had 45 chromosomes, with a single $X$ chromosome. TS is one of the most frequent human chromosomal disorders, affects one girl for every 2500 newborns alive. As fetal chromosomal anomaly is even higher frequency, $99 \%$ of pregnancies with fetus $45 \mathrm{X}$ end in spontaneous abortion, a fact that occurs mainly in the first trimester so that only those fetuses with "moderate forms" syndrome Turner are viable?

The phenotypic expression of ST can be explained based on three theories: (1) state of haploinsufficiency of genes that are normally expressed in the two sex chromosomes and that would escape the phenomenon of inactivation, (2) imprinting phenomenon that modifies the expression of the gene depending on their paternal or maternal origin, and (3) non-specific defects secondary to chromosomal imbalance. The wide spectrum of somatic signs present in the ST indicates that different genes located on the $\mathrm{X}$ chromosome may be responsible for the complete phenotype ${ }^{3,7}$.

Cases diagnosed with ST are usually due to incidental findings such as pterigium colli, hidrops fetalys by prenatal ultrasound from 11 at the 13.6 weeks of gestational age, and ocasionally the abnormal levels of biochemical markers of the first trimester, such as the fraction of human chorionic gonadotropin $(\beta)$, alpha-fetoprotein and the evidence of the cytogenetic study in villus biopsy corrals or in amniotic fluid and currently with the study of fetal DNA in maternal plasma that provides definitive information ${ }^{3}$. Genetic counseling must be carried out in a multidisciplinary manner with the participation of the endocrinologist pediatrician who is the one who knows best the long-term evolution and all aspects related to the prognosis and quality of life of these patients ${ }^{4}$.

The TS is a well-defined clinical entity that in recent years has experienced considerable progress in terms of knowledge of its pathophysiology and the treatment of comorbidities. The scientific knowledge has allowed to change some aspects such as the realization of an early diagnosis, timely treatment of short stature, treatment of hypogonadism, possibility of pregnancies through assisted reproduction programs, psychological support, social help through the groups of support and a better treatment of the associated pathology, greater life expectancy, better quality of life, and satisfactory incorporation into the social and labor world ${ }^{1}$. The mortality associated with TS is 3 times higher than in the normal population and the life expectancy is reduced in 13 years, especially in $45 \mathrm{X}$ women, with cardiovascular disease being the main cause of death. A multidisciplinary team is needed that also includes the endocrinologist pediatrician, geneticist, cardiologist, nephrologist, otolaryngologist, surgeon, ophthalmologist, gynecologist, psychologist, and orthopedist able to assume the diagnosis and treatment of all comorbidities ${ }^{2,3}$.

Historically, congenital diaphragmatic hernia $(\mathrm{CDH})$ was considered a surgical emergency; newborns were immediately taken to the operating room as soon as possible with the belief that reducing the abdominal contents of the chest would relieve lung compression. However, after a short post-operative period, they presented respiratory deterioration, high pulmonary vascular resistance, right-to-left shunting, hypoxemia, and death in the final period resulting from respiratory failure. Therefore, a period of medical stabilization and delay in repair was proposed in an attempt to improve the general condition of the newborn with HDC. The survival rate of newborns with $\mathrm{CDH}$ ranges from 60 to $90 \%$ through the use of physiological treatment strategies including gentle ventilation techniques, high-frequency ventilation, cardiovascular pharmacological support, and extracorporeal membrane oxygenation (ECMO) with gradual improvement in survival $\left.\right|^{5,6}$.

ST has been described in association with other disorders such as autoimmune diseases including inflammatory bowel disease, rheumatoid arthritis, autoimmune thyroiditis, diabetes mellitus, and, in rare cases, coexisting with Klippel-Feil syndrome ${ }^{8}$; however, after the extensive review of literature, there are no reports of diaphragmatic defects with TS, reason for the importance of the presentation of this clinical case.

\section{Ethical disclosures}

Protection of human and animal subjects. The authors declare that no experiments were performed on humans or animals for this study.

Confidentiality of data. The authors declare that they have followed the protocols of their work center on the publication of patient data. 
Right to privacy and informed consent. The authors have obtained the written informed consent of the patients or subjects mentioned in the article. The corresponding author is in possession of this document.

\section{References}

1. Marin A, Weir-McCall JR, Webb DJ, van Beek EJ, Mirsadraee S. Imaging of cardiovascular risk in patients with turner's syndrome. Clin Radiol. 2015;70:803-14.

2. Pinsker JE. Clinical review: turner syndrome: updating the paradigm of clinical care. J Clin Endocrinol Metab. 2012;97:E994-1003.
3. Pinto ME, Fuentes SJ, Montaño $\mathrm{Cl}$, Morales AM. Síndrome de turner en el recién nacido: a propósito de un caso. Rev Méd Cient Luz Vida. 2014;5:49-51.

4. Pober BR. Genetic aspects of human congenital diaphragmatic hernia. Clin Genet. 2008;74:1-5.

5. Stolar CJ, Dillon PW. Congenital diaphragmatic hernia and eventration. In: Pediatrics Surgery. $7^{\text {th }}$ ed. Philadelphia, PA: Mosby Elseviers; 2012. p. 809-824.

6. Andelka S, Zoran M, Ivona D, Zorica J, Ivana B. Congenital herniation through the foramen morgagni. Clinical presentation, diagnosis and treatment in pediatric population. Cent Eur J Med. 2010;61:131-5.

7. Saenger $P$, Wikland KA, Conway GS, et al. Recommendations for the diagnosis and management of turner syndrome. J Clin Endocrinol Metab. 2001;86:3061-9

8. Morales HA, Gómez VL, Rivera AM, Briceño GR, Toledo OE, Cornelio GR Síndrome de turner mosaico 45, X/46, XX/47, XXX asociado al síndrome de klippper-feil. Bol Med Hosp Infant Mex. 2009;66:446-50. 